\section{Aptidão física e trabalho físico pesado: como interagem para a ocorrência de distúrbio musculoesquelético?}

\author{
How do physical fitness and heavy physical work \\ interact in the occurrence of musculoskeletal \\ disorders?
}

\author{
Aptitud física y trabajo físico pesado: ¿cómo \\ interactúan entre sí para la aparición de \\ trastornos musculoesqueléticos?
}

\author{
1 Programa de Pós-graduação \\ em Saúde, Ambiente e \\ Trabalho, Universidade \\ Federal da Bahia, Salvador \\ Brasil. \\ Correspondência \\ R. C. P. Fernandes \\ Programa de Pós-graduação \\ em Saúde, Ambiente e \\ Trabalho, Universidad \\ Federal da Bahia. \\ Largo do Terreiro de Jesus, \\ Salvador, $B A$ \\ 40026-010, Brasil. \\ ritafernandes@ufba.br
}

\begin{abstract}
A cross-sectional study investigated the association between self-reported physical fitness and musculoskeletal disorders in the neck, shoulder, or upper back among workers in 14 plastics factories in Salvador, Bahia State, Brazil. Physical fitness was assessed on a scale from 0 to 5 . Cases were defined as self-reported pain in the previous 12 months, lasting more than a week or having monthly minimum frequency, with restrictions at work or seeking medical care, or where respondents' severity was greater than 2 (on a scale from 0 to 5). Logistic regression was performed to investigate statistical interaction between physical fitness and physical demands from work in the occurrence of musculoskeletal disorders. Precarious physical fitness resulted in 3.19 times greater odds of musculoskeletal disorders among workers exposed to light physical demands on the job. Among workers exposed to heavy physical demands, physical fitness failed to protect against musculoskeletal disorders. Heavy physical work was always associated with high prevalence of musculoskeletal disorders. Despite the importance of physical fitness, physical exercise programs should not be used to replace improvements in working conditions.
\end{abstract}

Musculoskeletal Diseases; Cumulative Trauma Disorders; Physical Exertion
Adauto Luis Moreira Mascarenhas 1 Rita de Cássia Pereira Fernandes ${ }^{1}$

\section{Resumo}

Estudo transversal com 577 trabalhadores investigou associação entre aptidão física autopercebida e distúrbios musculoesqueléticos em pescoço, ombro ou parte alta das costas, em trabalhadores de 14 indústrias de plástico, em Salvador, Bahia, Brasil. A aptidão física autopercebida foi avaliada em escala de 0-5 pontos. Caso de distúrbios musculoesqueléticos: dor nos últimos 12 meses, superior a uma semana ou frequência mensal, restringindo o trabalho, ou provocando assistência médica, ou gravidade 3 ou maior, em escala de 0-5. A regressão logística investigou interação entre aptidão física e demanda física no trabalho para ocorrência de distúrbios musculoesqueléticos. Precária aptidão física resultou em 3,19 vezes a chance de distúrbios musculoesqueléticos, mas apenas entre aqueles submetidos a baixa demanda física no trabalho. Entre expostos a alta demanda física no trabalho, boa aptidão física não foi fator de proteção para distúrbios musculoesqueléticos, ou seja, trabalho físico pesado está associado a alta prevalência de distúrbios musculoesqueléticos, mesmo quando trabalhadores referem boa aptidão física. Apesar da importância da boa aptidão física, programas de atividade física não devem substituir intervenções nas condições de trabalho.

Doenças Musculoesqueléticas; Transtornos Traumáticos Cumulativos; Esforço Físico 


\section{Introdução}

Os distúrbios musculoesqueléticos podem ser resultantes de uma modalidade organizacional e biomecânica do trabalho que demanda adoção de posturas anômalas, repetitividade de movimentos e manuseio de carga com esforço físico intenso, para realização de tarefas, com ritmos de trabalho que ultrapassam as capacidades fisiológicas e psicológicas dos trabalhadores ${ }^{1}$.

Os distúrbios musculoesqueléticos são de natureza multifatorial, determinam impactos econômicos, sociais e pessoais para os sujeitos comprometidos. São quadros clínicos do sistema musculoesquelético adquiridos pelo trabalhador quando submetido a determinadas condições de trabalho. Tais quadros clínicos se caracterizam pela ocorrência de vários sintomas, concomitantes ou não, de aparecimento insidioso, geralmente nos membros superiores, tais como dor, parestesia, sensação de peso e fadiga 2 .

Alguns estudos têm sugerido que a prática regular de atividade física poderia se constituir em um potencial fator de proteção para populações de trabalhadores 3,4,5; embora, também existam estudos que não observam melhorias neste sentido, ou são inconclusivos 6,7.

A atividade física regular poderia resultar na aquisição de um conjunto de atributos que constituem a aptidão física relacionada à saúde. Segundo Caspersen et al. 8, fazem parte deste conjunto a resistência cardiorrespiratória, a resistência e força musculares, a composição corporal e a flexibilidade.

Em nível adequado, a aptidão física propicia mais energia para o trabalho, lazer e outras atividades da vida diária, reduzindo a probabilidade de adoecimento. No entanto, há importante lacuna no conhecimento acerca do papel da aptidão física para a ocorrência de distúrbios musculoesqueléticos entre trabalhadores.

É bem conhecida, entre profissionais da Saúde Ocupacional, uma concepção de que trabalhadores melhor condicionados do ponto de vista físico estariam aptos para trabalhos que implicam grande esforço físico, independente das condições nas quais este trabalho seja realizado. Literatura científica, no entanto, não corrobora esta concepção 1 .

Uma questão que está posta aos pesquisadores dos distúrbios musculoesqueléticos relacionados ao trabalho é sobre o papel da aptidão física relacionada à saúde na ocorrência desses distúrbios em trabalhadores.

Em revisão da literatura, não foram encontrados estudos que tenham avaliado a aptidão física relacionada à saúde na sua relação com os distúrbios musculoesqueléticos, nem considerando todos os atributos que a compõem, por meio da percepção individual. Além disso, em estudos que avaliam aptidão física relacionada à saúde, em geral, os autores têm optado por investigar os atributos específicos (flexibilidade, aptidão cardiorrespiratória, força muscular, percepção corporal) 9,10 de forma isolada, ou a investigam por meio de técnicas de medidas diretas e não pelo autorregistro 11 .

Considerando-se que os distúrbios musculoesqueléticos em trabalhadores representam um importante problema de saúde pública, este estudo investigou a associação entre aptidão física autopercebida e os distúrbios musculoesqueléticos localizados em região de pescoço, ombro ou parte alta do dorso, em trabalhadores de indústrias de plástico, seguindo estudo exploratório com esta população no qual a aptidão física autopercebida esteve entre os fatores associados aos distúrbios musculoesqueléticos em pescoço, ombro ou parte alta do dorso 12 .

\section{Métodos}

Os dados analisados foram obtidos por meio de um estudo de corte transversal cuja populaçãoalvo abrangeu todos os trabalhadores inseridos em atividades de manutenção e operação de 14 indústrias de plástico, em Salvador, Bahia, Brasil.

Do total de 1.177 trabalhadores, retirou-se uma amostra aleatória estratificada proporcional, que manteve a proporcionalidade entre a quantidade de trabalhadores de cada unidade fabril e aquela existente na população-alvo.

O tamanho mínimo para a amostra, 557 indivíduos, foi calculado considerando-se um grau de precisão absoluta de $4 \%$, nível de $95 \%$ de confiança, prevalência esperada de $50 \%$ e um efeito de desenho de 1,4. Aumentou-se o tamanho mínimo da amostra originalmente calculada, a fim de incluir possíveis perdas.

Para a coleta de dados, realizada no ano de 2002, um questionário foi aplicado por entrevistador treinado previamente, dentro de cada fábrica participante, durante o expediente de trabalho, assegurando privacidade, visando minimizar possíveis vieses de informação.

O questionário continha perguntas a respeito de: condições sociodemográficas (idade, sexo, estado civil, escolaridade, presença de filhos menores de dois anos de idade); história ocupacional na empresa atual e na vida laboral pregressa, incluindo vínculos formais e informais, jornada de trabalho, quantidade de hora extra, e de horas trabalhadas na semana, demanda física no trabalho, demanda psicossocial no trabalho; uso de fumo, medicamentos, bebidas alcoólicas; traba- 
lho doméstico, atividade física de lazer e aptidão física. Incluíram-se questões sobre outras informações de saúde (antecedentes de fratura, história de diabetes, artrite reumatoide e hipotireoidismo). A inclusão de todas as perguntas acima visou assegurar uma mais completa obtenção de variáveis para explicação do efeito, ou seja, de todos os potenciais confundidores da associação sob estudo. A variável "presença de filhos menores de dois anos" foi incluída porque tem sido citada na literatura como fator associado aos distúrbios musculoesqueléticos em extremidades superiores, já que o cuidado com filhos menores pode implicar sobrecarga física, em especial, para este segmento corporal 13. Para medida do efeito, distúrbios musculoesqueléticos em pescoço, ombro ou parte alta do dorso, registraramse as questões do Nordic Musculoskeletal Questionnaire (NMQ) 14, com itens para avaliação de gravidade. Definiu-se como caso de distúrbios musculoesqueléticos em pescoço, ombro ou parte alta do dorso a referência a dor em região de pescoço, ombro ou parte alta do dorso, nos últimos 12 meses, com duração de mais de uma semana ou frequência mínima mensal. Esta dor deveria estar associada a um ou mais dos seguintes itens: gravidade maior ou igual a 3 , em uma escala ordinal de 0 a 5 , com qualificadores verbais explicativos nas extremidades $(0=$ nenhuma dor; 5 = dor insuportável); busca de atenção médica para o problema; ausência ao trabalho; mudança de trabalho.

Investigou-se a aptidão física por meio do autorregistro de trabalhadores a respeito da sua percepção da aptidão física, em uma escala ordinal de seis pontos ( 0 a 5), tendo como âncoras ou qualificadores verbais explicativos nas extremidades as palavras "precária" (0) e "excelente" (5). Após um bloco de perguntas sobre atividade física de lazer, que não são objeto do presente estudo, perguntou-se, para medir de forma autorreferida a aptidão física: "Como você considera seu condicionamento (preparo) físico?”. Para fins de melhor acessibilidade da linguagem, as palavras "condicionamento" e "preparo" foram incluídas na questão. A aptidão física autopercebida foi definida como "boa" quando a pontuação era maior do que 3 na escala anteriormente referida, enquanto que os que marcaram 3 ou menos foram categorizados como aptidão física autopercebida "precária".

Demanda física no trabalho foi avaliada por meio de 11 questões com uma escala ordinal de 0 a 5 , tendo como qualificadores verbais explicativos nas extremidades as palavras "jamais" (0) e "o tempo todo" (5), para a variável medida em duração, ou as palavras "fraca" (0) e "muito forte" (5), para a variável medida em intensidade. As questões se referiam a: movimentos repetitivos com as mãos, força exercida com mãos e braços, postura geral de trabalho (sentado, andando e em pé), trabalho com braços acima do nível dos ombros, tronco inclinado, tronco rodado e manuseio de carga. Com a escala e o uso de qualificadores, buscou-se minimizar os problemas de confiabilidade e validade detectados em outros tipos de escala 15. Procedeu-se à sumarização das variáveis de demanda física no trabalho, criandose um índice baseado nas análises univariadas e na evidência de associação na literatura entre as variáveis e o desfecho (distúrbios musculoesqueléticos em pescoço, ombro ou parte alta do dorso). As variáveis selecionadas foram "trabalho com braços acima do nível dos ombros", "movimentos repetitivos com as mãos" e "manuseio de carga", cujas escalas mediam a duração durante a jornada de trabalho $(0=$ jamais a $5=$ o tempo todo), além da variável "força exercida com mãos e braços", cuja escala media intensidade $(0=$ fraca a 5 = muito forte). A classificação de exposição à demanda física no trabalho, por meio do índice, considerou o corte no terceiro quartil (ou percentil 75), ou seja, os indivíduos classificados como expostos somavam 15 ou mais pontos para as variáveis selecionadas, ou seja, um elevado grau de exposição, considerando as maiores pontuações nas escalas.

A demanda psicossocial no trabalho foi medida com a aplicação do Job Content Questionnaire (JCQ) 16, cujas questões permitiram a obtenção dos escores para demanda psicológica, controle e suporte social, por meio dos quais foi definida uma variável de exposição psicossocial, utilizando-se o critério proposto por Devereux et al. 17 que consideram alta exposição à demanda psicossocial a satisfação de pelo menos duas das seguintes condições: alta demanda psicológica, baixo controle, baixo suporte.

\section{Análise dos dados}

A investigação da associação principal implicou a análise de variáveis intervenientes a fim de se conhecer o efeito independente da variável aptidão física autopercebida sobre a variável distúrbios musculoesqueléticos em pescoço, ombro ou parte alta do dorso, controlado por possíveis modificadores de efeito e ou ajustado por possíveis confundidores.

Realizou-se inicialmente uma abordagem descritiva dos dados, seguida de análise tabular estratificada. A análise de regressão logística binária, não-condicional foi empregada para verificar a associação entre aptidão física autopercerbida e distúrbios musculoesqueléticos em pescoço, ombro e parte alta do dorso. A seleção 
das variáveis para modelagem tomou como base o resultado da análise estratificada.

Interação foi identificada comparando-se os graus de ajustamento dos modelos de regressão logística, completo e sem os termos de interação (termos-produto), por meio do teste de razão da verossimilhança, com modelagem do tipo backward. Variável de interação foi aquela cujo termo-produto melhorou o ajuste do modelo em níveis estatisticamente significantes (alfa $=0,20$ ).

Uma vez constatada interação estatística, os resultados finais da medida da associação principal foram apresentados pelos estratos da variável de interação - isto é, foram apresentados os resultados da medida de associação principal controlados pela modificadora de efeito ou variável de interação. Constatada uma variável como de interação esta não foi avaliada como confundidora. Variável de confusão seria aquela que ao ser retirada do modelo saturado produzisse alteração de $15 \%$ ou mais na medida da associação principal ou na amplitude do seu intervalo de confiança.

Os programas empregados para a análise estatística dos dados foram Epi-Info 6.04 (Centers for Disease Control and Prevention, Atlanta, Estados Unidos) e SPSS 9.0 (SPSS Inc., Chicago, Estados Unidos).

O projeto desta pesquisa foi aprovado pelo Comitê de Ética em Pesquisa do Instituto de Saúde Coletiva da Universidade Federal da Bahia. Um Termo de Consentimento Livre e Esclarecido (TCLE) foi assinado por cada participante antes de responder ao questionário.

\section{Resultados}

Estudaram-se 577 indivíduos, 179 mulheres e 398 homens.

Na Tabela 1 encontram-se os dados referentes à aptidão física autopercebida, variável independente principal do estudo, de acordo com sexo, idade, situação conjugal, escolaridade, filhos e demanda física no trabalho. Os homens mostraram-se mais aptos que as mulheres, bem como os sujeitos que tinham menos do que segundo grau completo em relação aos indivíduos com segundo grau completo ou nível superior.

A distribuição da exposição com as quatro variáveis que compuseram o índice para demanda física no trabalho foi descrita pelo ponto da escala de resposta ( 0 a 5) nos percentis 25,50 e 75 . Movimentos repetitivos com as mãos estavam presentes durante quase toda a jornada, pois o ponto 5 da escala foi atingido já no percentil 50. O manuseio de carga também ocupa boa parte da jornada e o ponto 3 da escala é atingido no percentil 50. As tarefas que implicam adoção de postura com braços elevados acima do nível dos ombros estão presentes na jornada de grande parte dos trabalhadores. Por fim, a variável "força muscular com os braços e mãos" evidencia a alta demanda física das tarefas, pois a força exigida é de 3 já no percentil 25 (Tabela 2).

Constatou-se que a variável demanda física no trabalho modificava o efeito da variável independente principal - aptidão física autopercebida, ou seja, a ocorrência de distúrbios musculoesqueléticos em pescoço, ombro ou parte alta do dorso resulta da interação entre as variáveis aptidão física autopercebida e demanda física no trabalho. Na presença do trabalho físico intenso ("alta demanda física no trabalho"), a estimativa da associação entre aptidão física autopercebida e distúrbios musculoesqueléticos em pescoço, ombro ou parte alta do dorso é diferente da associação entre essas quando o trabalho físico é de leve a moderado ("baixa demanda física no trabalho"). A apresentação dos resultados visou explicitar esses achados.

Desde a fase da análise tabular estratificada, suspeitou-se de interação entre aptidão física autopercebida e demanda física no trabalho para a ocorrência de distúrbios musculoesqueléticos em pescoço, ombros e parte alta do dorso, do tipo antagônica. Na Tabela 3 estão descritos esses resultados da análise tabular estratificada, apresentando-se a prevalência, razão de prevalência e intervalos de 95\% de confiança (IC95\%) para efeitos combinados de demanda física no trabalho e aptidão física autopercebida em relação aos distúrbios musculoesqueléticos em pescoço, ombro ou parte alta do dorso. Entre os trabalhadores com menor demanda física no trabalho, a prevalência de distúrbios musculoesqueléticos em pescoço, ombro ou parte alta do dorso para os que referem boa aptidão física é de $7 \%$, elevando-se para $20 \%$ entre os que referem precária aptidão física. Portanto, entre esses com menor demanda física no trabalho, a prevalência de distúrbios musculoesqueléticos em pescoço, ombro ou parte alta do dorso é cerca de três vezes maior para os que se consideram com precária aptidão física autopercebida, comparados aos que referem boa aptidão física autopercebida. No entanto, entre todos aqueles com alta demanda física no trabalho, a prevalência de distúrbios musculoesqueléticos em pescoço, ombro ou parte alta do dorso é sempre alta, tanto para os que se sentem com boa aptidão física autopercebida $(30,7 \%)$, quanto para os que referem aptidão física autopercebida precária $(36,7 \%)$. Ou seja, o possível risco da falta de uma boa aptidão física praticamente desaparece na presença do trabalho físico pesado. Este resultado sugeria, já na 
Características da população de estudo de acordo com a aptidão física autopercebida, em trabalhadores da indústria de plástico. Salvador, Bahia, Brasil.

\begin{tabular}{|c|c|c|c|c|c|}
\hline \multirow[t]{3}{*}{ Variáveis } & \multicolumn{4}{|c|}{ Aptidão física autopercebida } & \multirow[t]{3}{*}{ Valor de $p$} \\
\hline & \multicolumn{2}{|c|}{ Precária } & \multicolumn{2}{|c|}{ Boa } & \\
\hline & $\mathrm{n}$ & $\%$ & $\mathrm{n}$ & $\%$ & \\
\hline Sexo & & & & & 0,0001 \\
\hline Homens & 181 & 61,8 & 216 & 76,9 & \\
\hline Mulheres & 112 & 38,2 & 65 & 23,1 & \\
\hline Idade (anos) & & & & & 0,62 \\
\hline$\leq 25$ & 82 & 28,0 & 69 & 24,6 & \\
\hline $25-40$ & 171 & 58,4 & 174 & 61,9 & \\
\hline$\geq 40$ & 40 & 13,7 & 38 & 13,5 & \\
\hline Excesso de peso & & & & & 0,035 \\
\hline Sim & 109 & 38,9 & 83 & 30,4 & \\
\hline Não & 171 & 61,1 & 190 & 69,6 & \\
\hline Situação conjugal & & & & & 0,43 \\
\hline Casado/Vive junto & 183 & 62,5 & 166 & 59,3 & \\
\hline Solteiro/Separado/Divorciado & 110 & 37,5 & 114 & 40,7 & \\
\hline Escolaridade & & & & & 0,01 \\
\hline Até 2ograu incompleto & 156 & 53,2 & 179 & 63,7 & \\
\hline 2o grau completo/superior & 137 & 46,8 & 102 & 36,3 & \\
\hline Ter filhos $<2$ anos & & & & & 0,75 \\
\hline Sim & 39 & 13,3 & 35 & 12,5 & \\
\hline Não & 254 & 86,7 & 246 & 87,5 & \\
\hline Alta demanda física no trabalho & & & & & 0,97 \\
\hline Expostos & 79 & 27,1 & 75 & 27,1 & \\
\hline Não-expostos & 212 & 72,9 & 202 & 72,9 & \\
\hline Trabalho doméstico (horas/semana) & & & & & 0,83 \\
\hline$\geq 5$ & 136 & 46,4 & 128 & 45,6 & \\
\hline$<5$ & 157 & 53,6 & 153 & 54,4 & \\
\hline Anos de vida laborativa (anos) & & & & & 0,94 \\
\hline$\geq 13$ & 151 & 51,5 & 144 & 51,2 & \\
\hline$<13$ & 142 & 48,5 & 137 & 48,8 & \\
\hline
\end{tabular}

análise estratificada, uma interação estatística entre demanda física no trabalho e aptidão física autopercebida para a ocorrência de distúrbios musculoesqueléticos em pescoço, ombro ou parte alta do dorso. Portanto, evidenciou-se interação antagônica, conforme os resultados das Tabelas 3 e 4 revelam.

A análise multivariada confirmou a associação entre aptidão física e distúrbios musculoesqueléticos em pescoço, ombro ou parte alta do dorso, com modificação deste efeito pela variável demanda física no trabalho. A Tabela 4 mostra os resultados da regressão logística múltipla para análise de interação estatística. Observou-se interação entre aptidão física au- topercebida e demanda física no trabalho. Os trabalhadores que se percebem com uma precária aptidão tiveram 3,19 vezes a chance de distúrbios musculoesqueléticos em pescoço, ombro ou parte alta do dorso em comparação aos que apresentaram uma boa aptidão física autopercebida, mas isto ocorreu apenas entre aqueles com baixa exposição à demanda física no trabalho. Por outro lado, entre os expostos ao trabalho físico pesado, observaramse altas prevalências de distúrbios musculoesqueléticos em pescoço, ombro ou parte alta do dorso, seja entre aqueles com boa aptidão física autopercebida, seja entre os que se percebiam com aptidão física precária (razão de chances 
Tabela 2

Demandas físicas no trabalho (postura, força e movimento) em trabalhadores da indústria de plástico. Salvador, Bahia, Brasil.

\begin{tabular}{|c|c|c|c|c|}
\hline Variáveis de demanda física & Âncoras nas extremidades das escalas & P25 & P50 & P75 \\
\hline Força muscular com braços e mãos & $0=$ fraca; 5 = muito forte & 3 & 4 & 5 \\
\hline Com braços elevados acima dos ombros & $0=$ jamais $; 5=0$ tempo todo & 0 & 2 & 3 \\
\hline Movimentos repetitivos com as mãos & $0=$ jamais $; 5=0$ tempo todo & 3 & 5 & 5 \\
\hline Trabalho exige levantamento de carga & $0=$ jamais $; 5=0$ tempo todo & 1 & 3 & 4 \\
\hline
\end{tabular}

Tabela 3

Resultados da análise tabular estratificada para os efeitos combinados de demanda física no trabalho (DFT) e aptidão física autopercebida (AFAP) para a ocorrência de distúrbios musculoesqueléticos em pescoço, ombro ou parte alta do dorso *, em trabalhadores de indústria de plástico. Salvador, Bahia, Brasil.

\begin{tabular}{lcccc}
\hline Variável & $\mathbf{n}$ & Prevalência (\%) & RP & IC95\% \\
\hline DFT $=$ 0; AFAP $=0$ & 202 & 7,9 & 1,00 & - \\
DFT $=0 ;$ AFAP $=1$ & 212 & 22,6 & 2,86 & $2,48-3,24$ \\
DFT $=1 ;$ AFAP $=0$ & 75 & 30,7 & 3,89 & $3,20-4,58$ \\
DFT $=1 ;$ AFAP $=1$ & 79 & 36,7 & 4,64 & $3,95-5,33$ \\
\hline
\end{tabular}

AFAP = 0: boa; AFPA = 1: precária; DFT = 0: baixa exposição, DFT = 1: alta exposição.

* Dor nos últimos 12 meses, com duração de mais de uma semana ou com frequência mínima mensal que motivou procurar o médico ou afastar-se do trabalho, com grau 3 ou mais em escala de 0 a 5, em região de pescoço, ombros ou parte alta das costas.

Tabela 4

Resultados da regressão logística para a associação entre aptidão física autopercebida e distúrbios musculoesqueléticos em pescoço, ombro ou parte alta do dorso *, de acordo com a demanda física no trabalho, em trabalhadores da indústria de plástico. Salvador, Bahia, Brasil.

\begin{tabular}{lcc}
\hline Modelos & RC & IC95\% \\
\hline Alta demanda física no trabalho & & - \\
$\quad$ Boa aptidão física autopercebida & 1,00 & $0,60-2,10$ \\
$\quad$ Precária aptidão física autopercebida & 1,20 & - \\
Baixa demanda física no trabalho & 1,00 & $1,69-6,04$ \\
$\quad$ Boa aptidão física autopercebida & 3,19 &
\end{tabular}

RC: razão de chances; IC95\%: intervalo de 95\% de confiança.

* Dor nos últimos 12 meses, com duração de mais de uma semana ou com frequência mínima mensal que motivou procurar o médico ou afastar-se do trabalho ou mudar de trabalho, com grau 3 ou mais em escala de 0 a 5, em região de pescoço, ombros ou parte alta do dorso.

Nota: $p=0,000$ na avaliação da interação estatística. Não houve variável confundidora da associação principal. 
$-\mathrm{RC}=1,20$ ). A RC observada indica o efeito antagônico - o possível risco da falta de uma boa aptidão física para a ocorrência de distúrbios musculoesqueléticos em pescoço, ombro ou parte alta do dorso, constatado entre os que não exerciam trabalho físico pesado, praticamente desaparece na presença do trabalho físico exaustivo.

Nenhuma das demais variáveis independentes foi confundidora para a associação principal, ou seja, para a associação entre aptidão física autopercebida e distúrbios musculoesqueléticos em pescoço, ombro ou parte alta do dorso. Assim, os resultados do modelo final apresentam o achado de interação sem ajuste por outras variáveis, já que nenhuma das demais covariáveis confundiu a associação com a magnitude adotada no estudo.

\section{Discussão}

Os trabalhadores que apresentaram aptidão física autopercebida precária tiveram cerca de três vezes a prevalência de adoecimento (distúrbios musculoesqueléticos em pescoço, ombro ou parte alta do dorso) dos que apresentaram boa aptidão física autopercebida, mas apenas entre os expostos a baixa demanda física no trabalho, ou seja, entre aqueles cujo trabalho físico era mais leve. Entre aqueles submetidos ao trabalho físico pesado, as prevalências de dor em região de pescoço, ombros e parte alta das costas foram muito elevadas sempre, seja entre os que se percebiam com boa aptidão física, seja entre aqueles que percebiam sua aptidão como precária. O efeito da aptidão física sobre a ocorrência de distúrbios musculoesqueléticos em pescoço, ombro ou parte alta do dorso se modifica na presença do trabalho físico pesado. Neste estudo, a interação antagônica evidencia que o possível risco da falta de uma boa aptidão física para a ocorrência de distúrbios musculoesqueléticos em pescoço, ombro ou parte alta do dorso quase se anula quando o indivíduo se expõe ao trabalho físico exaustivo, que tem sido, de acordo com vasta literatura, fortemente associado aos distúrbios musculoesqueléticos 1,14. Este resultado vai ao encontro dos estudos que revelam a superioridade das intervenções sobre as condições de trabalho comparadas aos atributos físicos individuais do trabalhador (mais ou menos apto fisicamente) para prevenção dos distúrbios musculoesqueléticos ${ }^{1}$ e pode ajudar a questionar a adoção da ginástica laboral como medida isolada efetiva para o controle deste agravo em trabalhadores.

Os achados relacionados ao papel de uma aptidão física precária entre os que estavam em trabalho mais leve podem ser considerados compatíveis com estudos que sugerem que sejam dados estímulos para a prática de atividade física de lazer com objetivos de redução de morbidades musculoesqueléticas, principalmente para trabalhadores envolvidos em ocupações de natureza sedentária 3. Para van den Heuvel et al. 18,19, trabalhadores que tinham ocupações com características sedentárias e que praticavam atividade física de lazer apresentavam menos registros de licença médica devido a morbidades do que aqueles que não tinham essa prática. Embora as ocupações da população do presente estudo não possam ser caracterizadas como de natureza sedentária, os trabalhadores que apresentaram efeito da aptidão física autopercebida foram aqueles que tinham trabalho físico mais leve, portanto, mais próximos daqueles estudados por van den Heuvel et al. 18,19 no que tange à característica do trabalho quanto à exigência física.

Por outro lado, para os trabalhadores expostos a demandas físicas relevantes no trabalho, ou seja, ao trabalho físico pesado, a ocorrência de dor em região de pescoço, ombro e parte alta do dorso foi sempre muito elevada, independentemente da aptidão física autopercebida. As prevalências acima de $30 \%$ entre esses trabalhadores devem ser consideradas, especialmente, tomando em conta a definição de caso de distúrbios musculoesqueléticos em pescoço, ombro ou parte alta do dorso que foi dor com duração de mais de uma semana ou frequência mínima mensal que tenha determinado busca de atenção médica ou redução da capacidade para o trabalho. Entre esses, a percepção de aptidão física não repercutiu sobre a ocorrência dos distúrbios musculoesqueléticos, sendo as prevalências muitas próximas para quem se percebe com boa aptidão ou com aptidão precária. Neste caso, é possível supor que outras medidas de proteção que reduzam a exposição do trabalhador ao trabalho físico pesado se fazem necessárias a fim de controlar a morbidade musculoesquelética.

No presente estudo, a exposição à demanda física no trabalho foi medida por meio do autorregistro dos trabalhadores, que pode representar a superação do limite de avaliação de exposição a demandas físicas baseada em títulos de ocupação ou questões com respostas dicotômicas. As questões utilizadas para avaliar a demanda física permitiram obter, para cada indivíduo, uma medida de exposição, com a utilização de uma escala ordinal de 6 pontos (de 0 a 5) com âncoras nas extremidades. Esta escala, que não requer a medida absoluta da exposição, mas que indica a mais alta e a mais baixa exposição por meio dos qualificadores ou âncoras, bem como a formulação mais geral das questões ("gestos repetitivos", 
“força muscular com os braços ou mãos"), pode ter permitido aos trabalhadores fornecerem as melhores respostas acerca da sua percepção da exposição, conforme critérios apontados como mais válidos e confiáveis por Stock et al. 15 a respeito de questões e escalas para medida de demanda física.

Os resultados sobre exposição à demanda física ocupacional revelam tarefas que se caracterizam pela realização de movimentos repetitivos com as mãos, implicando força com braços e mãos, presença de tarefas que implicam manuseio de carga e postura de braços elevados acima do nível dos ombros.

A escassez de estudos que investiguem a relação entre a aptidão física autopercebida e distúrbios musculoesqueléticos em pescoço, ombro ou parte alta do dorso, levou à busca de resultados que avaliassem a associação entre atividade física de lazer e distúrbios musculoesqueléticos (em geral e não apenas para a região corporal estudada), como a forma mais próxima para a presente discussão, haja vista ser por meio das práticas de atividade física (inclusive exercícios físicos) que podem ser mantidos, aprimorados ou desenvolvidos os atributos da aptidão física ${ }^{8}$.

Estudos que analisam a prática de atividade física de lazer, como forma de prevenção de distúrbios musculoesqueléticos, não têm mostrado consistência quanto à sua efetiva contribuição. Hildebrandt et al. 3 não encontraram associação entre a quantidade de horas gastas em participação em esportes ou outras atividades físicas e distúrbios musculoesqueléticos ou ausência ao trabalho devido a esses distúrbios em região lombar, pescoço, ombro e extremidades inferiores. Observaram, entretanto, que os trabalhadores que optavam por atividades sedentárias no lazer apresentavam significantemente maior prevalência de distúrbios musculoesqueléticos e ausências ao trabalho por este motivo em relação àqueles que gastavam menos tempo com atividades sedentárias no lazer, o que faz pensar em possível efeito protetor da atividade física de lazer para os distúrbios musculoesqueléticos.

É importante ressaltar que reduzir a demanda física no trabalho, ou seja, reduzir o esforço físico, o trabalho "pesado" ou "braçal", como habitualmente é referido nos ambientes de trabalho, respeitando os limites do corpo, parece ser uma prioridade. Isso está relacionado ao conceito de tolerância de carga, associado à prática das atividades 1 . Esse conceito sugere que, para minimizar o risco de uma atividade física (que implique sobrecarga física), deve-se planejála de forma que a carga imposta aos tecidos e estruturas corporais envolvidas, durante a sua execução, não exceda a tolerância da estrutura requerida. Por exemplo: durante uma atividade $\mathrm{a}(\mathrm{s})$ estrutura(s) corporal(ais) desenvolve(m) um padrão de carga que se repete. Quando a magnitude da carga imposta pela atividade é menor que a tolerância do tecido, a tarefa é considerada segura, e a diferença entre a carga imposta e a tolerância é considerada como margem de segurança. De forma contrária, quando a carga aplicada excede a tolerância das estruturas envolvidas, seja por exigências de alta carga ou de repetitividade, a atividade implica alto risco de lesão. Portanto, considerando que a alta demanda física no trabalho pode representar atividade física com alta carga que excede os limites do corpo, a ocorrência de distúrbios musculoesqueléticos em pescoço, ombro ou parte alta do dorso não consegue, nessas circunstâncias, ser minimizada por uma boa aptidão física. De acordo com o presente estudo, realizar atividades de trabalho que implicam sobrecarga com manutenção de braços elevados, uso de força com os braços, repetitividade, envolvendo levantamento de carga, determina alta morbidade, mesmo que o trabalhador se sinta globalmente bem condicionado fisicamente.

Considerações dessa natureza se contrapõem à ideia de que boa resistência e força muscular, bem como boa aptidão física global, independente das condições nas quais o trabalho físico seja realizado, conseguem proteger o trabalhador do desenvolvimento de distúrbios musculoesqueléticos, em geral, e distúrbios musculoesqueléticos em pescoço, ombro ou parte alta do dorso, em particular. É mais provável que o trabalho pesado promova a degradação de segmentos corporais com aparecimento de sintomas 20 . Pelo observado no presente estudo, as elevadas prevalências de distúrbios musculoesqueléticos em pescoço, ombro ou parte alta do dorso sugerem que as exigências físicas para o desempenho das tarefas no trabalho estavam além dos limites de capacidade de resposta física dos trabalhadores, acarretando efeitos sobre a saúde.

Considerando que a população do presente estudo é formada por trabalhadores, o conceito de aptidão física aqui utilizado é aquele relacionado à saúde, conforme já definido. Mas Caspersen et al. 8 também explicitam o conceito de aptidão física relacionada ao desempenho, atinente à aptidão física esperada para o atleta. Esses autores trazem como componentes desta aptidão agilidade, equilíbrio, coordenação, velocidade, potência e tempo de reação ${ }^{8}$. Esses são atributos esperados do desempenho atlético.

Esses conceitos subsidiam a relevante discussão acerca do que se pode esperar de um trabalhador no seu labor diário. A realização de tarefas ocupacionais difere, portanto, do que 
deve ser exigido e esperado, em termos de desempenho, de um atleta. O trabalhador deseja realizar suas tarefas com qualidade, ter o reconhecimento pelo que faz e ser bem remunerado, sem adoecer e sem se acidentar em consequência do trabalho 21 .

Apesar da aparente obviedade do parágrafo precedente, boa parte da morbidade ocupacional decorre do grau de exigência física posta aos sujeitos em seus locais e postos de trabalho. Além do trabalho físico pesado, as exigências sobre segmentos específicos do corpo, implicando força e repetitividade, estão entre os fatores mais relevantes no adoecimento musculoesquelético no mundo do trabalho 1,11,14.

Para Nindl \& Sharp 22, o desempenho físico pode ser melhorado por meio da participação em programas de exercícios planejados, com objetivos voltados para a melhoria das condições físicas de uma forma geral. Outros estudos 23,24 também consideram que a melhoria nos padrões de aptidão física, quando associada à prática regular de atividade física, pode possibilitar uma absorção melhor das situações vividas diariamente, bem como prover a base para um melhor desempenho funcional. Isto vai ao encontro dos achados do presente estudo para os trabalhadores em atividades mais leves, para os quais a falta de uma boa aptidão física representou possível risco para a morbidade musculoesquelética, ou dito de outra forma, a boa aptidão física foi suficiente para reduzir a morbidade musculoesquelética. Porém, o presente estudo constata que uma boa aptidão física não é suficiente para proteger aqueles submetidos a altas demandas de trabalho físico, ou seja, não sustenta a ideia de que, uma vez condicionado fisicamente, o trabalhador poderá enfrentar condições adversas de trabalho, sem adoecimento. Ou dito de outra forma, na presença do trabalho físico extenuante, que determinou altas prevalências de distúrbios musculoesqueléticos aos trabalhadores, o efeito de um possível risco da falta de uma boa aptidão física praticamente desapareceu.

Com base nos resultados observados e na vasta literatura epidemiológica a respeito de distúrbios musculoesqueléticos, as intervenções nos ambientes de trabalho - com redução das demandas físicas ou eliminação do trabalho físico pesado - devem se constituir prioridade para prevenção dos distúrbios musculoesqueléticos em pescoço, ombro ou parte alta do dorso.

Intervir sobre as condições de trabalho não é incompatível com a implantação de programas de atividade corporal voltados para a saúde, desde que estes sejam planejados a partir do conhecimento sobre o que os trabalhadores fazem no seu labor diário, sobre as exigências sobre os seus corpos em uma jornada de trabalho, de modo que um programa de educação física de fato contribua para a redução desta carga física e para o relaxamento das estruturas corporais. Qualquer proposta de programa voltada para o condicionamento cardiorrespiratório ou condicionamento muscular não pode prescindir da análise do tipo e natureza da atividade física já desempenhada pelo trabalhador em sua atividade ocupacional. O compromisso deve ser com a promoção do bem-estar e com a redução da fadiga, o que deve implicar profundas revisões das práticas habituais que vêm sendo realizadas em locais de trabalho, sob a denominação de ginástica laboral.

Os estudos que propõem programas de atividade física como forma de mitigação de efeitos dos distúrbios musculoesqueléticos ou proteção contra os distúrbios musculoesqueléticos têm se baseado no fato de que, trabalhando-se atributos físicos específicos, podem ser obtidos ganhos em desempenho musculoesquelético. Polito et al. 25 observaram que o treinamento de flexibilidade com o objetivo de melhorar a amplitude da flexão anterior de tronco teve efeito protetor para lombalgia. Além disso, estudo desenvolvido pela Agência Europeia de Saúde e Segurança no trabalho ${ }^{11}$, por meio de programas de treinamento no trabalho, demonstrou que o treinamento de força para os ombros reduziu as queixas de distúrbios musculoesqueléticos em pescoço. Pedersem 20 também considera ser possível desenvolver força, resistência e coordenação com exercícios físicos para prevenir distúrbios musculoesqueléticos em pescoço, ombro e região lombar. Cada um desses resultados deve ser compreendido em contexto laboral específico.

Limitações metodológicas características de estudos de corte transversal, como o viés de simultaneidade, não permitiram afastar a possibilidade de que os trabalhadores que percebiam sua aptidão como precária o tivessem feito por já terem desenvolvido as morbidades musculoesqueléticas (causalidade reversa). No entanto, os diferentes resultados entre aqueles que apresentaram uma precária ou uma boa aptidão física autopercebida, a depender da demanda física no trabalho, obtidos na análise de interação, minimizam essa possibilidade.

Não se pode afastar, em estudo de corte transversal com população de trabalhadores, o efeito sobrevivência do trabalhador sadio, neste caso, trabalhadores com distúrbios musculoesqueléticos em pescoço, ombro ou parte alta do dorso expostos ao trabalho físico pesado poderiam, antes do estudo, ter se afastado para ocupações com trabalho leve ou ter sido desligados da empresa por baixo desempenho decorren- 
te da dor. Esta é uma possibilidade de viés de seleção com vasta documentação na literatura 26 . Caso isso tivesse ocorrido, as prevalências de distúrbios musculoesqueléticos em pescoço, ombro ou parte alta do dorso, encontradas no presente estudo para o trabalho físico pesado, estariam subestimadas. A possibilidade de uma sobrevivência seletiva segundo a percepção de aptidão física entre aqueles que realizavam trabalho físico pesado também não pode ser excluída. No entanto, os resultados que revelam o papel da boa aptidão física apenas na ausência do trabalho físico exaustivo é compatível com a fisiologia do exercício e com a biomecânica dos distúrbios musculoesqueléticos, conforme já discutido.

Algumas estratégias do estudo visaram minimizar outros possíveis vieses em estudos transversais que investigam a relação saúde e trabalho. A fim de reduzir viés de informação por superestimativa da queixa ou da exposição, adotaramse algumas estratégias para minimizar o foco da pesquisa em distúrbios musculoesqueléticos. Considerando que, em geral, a sensibilidade de inquéritos a respeito de sintomas musculoesqueléticos é alta e, por vezes, a especificidade pode ser mais baixa, visou-se aumentá-la por meio do uso de critérios de gravidade na definição de caso. Os estudos de validade e confiabilidade com o NMQ evidenciam, em geral, boas validade e confiabilidade 27,28 .

O uso da aptidão física autopercebida pode ter a vantagem de incorporar todos os possíveis atributos que permitam ao indivíduo registrar sua percepção global acerca do seu estado físico. Como todo autorregistro, esta forma de medir a aptidão pode guardar diferenças quanto à validade e confiabilidade frente às medidas diretas, mas essas também apresentam seus limites de validade e confiabilidade 15 . Assim, o que parece relevante neste estudo é assinalar que os resultados foram obtidos a partir da percepção dos trabalhadores e considerando a plausibilidade biológica, fisiológica, biomecânica e ergonômica dos achados, acredita-se que outras modalidades de medida da aptidão física global (e não apenas medida de atributos específicos) poderão chegar a resultados semelhantes.

\section{Conclusões}

Os resultados revelam que o trabalho físico pesado determina alta prevalência de adoecimento, para o qual a aptidão física autopercebida não foi protetora. Indicam que ao invés de selecionar os trabalhadores supostamente mais aptos fisicamente para o exercício de atividades ocupacionais em condições penosas, nas quais haja alta exigência de demanda física, deve-se pensar na redução dessas exigências e na adequação das condições de trabalho, do ponto de vista biomecânico e organizacional. O estímulo às atividades físicas não deve sobrepor nem pode substituir as intervenções de melhoria dessas condições. Uma boa aptidão física, cuja melhor forma de obter é com a realização de atividade física regular, pode proteger a saúde de trabalhadores sedentários ou submetidos a baixa demanda física no trabalho, mas é insuficiente como medida de proteção à saúde diante de trabalho físico de alta exigência. 


\section{Resumen}

Este estudio transversal con 577 trabajadores investigó la asociación entre aptitud física autopercibida y trastornos musculoesqueléticos en cuello, hombro o parte alta de la espalda, en trabajadores de 14 industrias de plástico, en Salvador, Bahía, Brasil. La aptitud física fue evaluada en una escala de 0 a 5 puntos. Los casos de disturbios musculoesqueléticos: dolor en los últimos 12 meses, duración de más de una semana o incidencia mensual con restricción al trabajo o buscar asistencia médica, o gravedad 3 o mayor, en escala de 0 a 5. La regresión logística investigó la interacción entre aptitud física y demanda física en el trabajo para la aparición de trastornos musculoesqueléticos. La precaria aptitud física evidenció en 3,19 veces la posibilidad de trastornos musculoesqueléticos, pero sólo entre aquellos sometidos a una baja demanda física. Entre los expuestos a una alta demanda física, una buena aptitud física no fue un factor de protección para los trastornos musculoesqueléticos, o sea, el trabajo físico pesado se asocia con una alta prevalencia de trastornos musculoesqueléticos, aún cuando trabajadores refieren una buena aptitud física. Programas de actividad física no deben sustituir intervenciones en las condiciones de trabajo.

Enfermedades Musculoesqueléticas; Trastornos de Traumas Acumulados; Esfuerzo Físico

\section{Colaboradores}

Os autores contribuíram equitativamente na elaboração do artigo.

\section{Agradecimentos}

Agradecemos à Professora Jael Glauce da Fonseca pela tradução do resumo para o espanhol.

\section{Referências}

1. National Research Council. Musculoskeletal disorders and the workplace: low back and upper extremities. Washington DC: The National Academies Press; 2001.

2. Maeno M, Salerno V, Rossi DAG, Fuller R. Lesões por esforços repetitivos (LER), distúrbios osteomusculares relacionados ao trabalho (Dort), dor relacionada ao trabalho. Protocolos de atenção integral à saúde do trabalhador de complexidade diferenciada. http://bvsms.saude.gov.br/bvs/pu blicacoes/protocolo_ler_dort.pdf (acessado em Mar/2014).
3. Hildebrandt HV, Bongers PM, Dul J, van Dijk FJH, Kemper HCG. The relationship between leisure time, physical activities and musculoskeletal symptoms and disability in worker populations. Int Arch Occup Environ Health 2000; 73:507-18.

4. Ratzlaff CR, Gillies JH, Koehoorn MW. Work-related repetitive strain injury and leisure-time physical activity. Arthritis Rheum 2007; 57:495-500.

5. Morken T, Mageroy N, Moen BE. Physical activity is associated with a low prevalence of musculoskeletal disorders in the Royal Norwegian Navy: a cross sectional study. BMC Musculoskelet Disord 2007; 8:56. 
6. Schneider S, Becker S. Prevalence of physical activity among the working population and correlation with work-related factors: results from the first German National Health Survey. J Occup Health 2005; 47:414-23.

7. van Amelsvoort LGPM, Spigt MG, Swaen GMH, Kant IJ. Leisure time physical activity and sickness absenteeism; a prospective study. Occup Med (Lond) 2006; 56:210-2.

8. Caspersen CJ, Powell KE, Christenson GM. Physical activity, exercise, and physical fitness: definitions and distinctions for health-related research. Public Health Rep 1985; 100:126-31.

9. Araújo DSMS, Araújo CGS. Autopercepção corporal de variáveis da aptidão física relacionada à saúde. Rev Bras Med Esporte 2002; 8:37-49.

10. Strøyer J, Donbæk LJ. The role of physical fitness as risk indicator of increased low back pain intensity among people working with physically and mentally disabled persons: a 30 -month prospective study. Spine (Phila Pa 1976) 2008; 33:546-54.

11. European Agency for Safety and Health at Work. Work-related musculoskeletal disorders: prevention report. Luxembourg: Office for Official Publications of the European Communities; 2008.

12. Fernandes RCP, Assunção AA, Silvany Neto AM, Carvalho FM. Musculoskeletal disorders among workers in plastic manufacturing plants. Rev Bras Epidemiol 2010; 13:11-20.

13. Bjorkstén MG, Boquist B, Talback M, Edling C. Reported neck and shoulder problems in female industrial workers: the importance of factors at work and at home. Int J Ind Ergon 2001; 27:159-70.

14. Kourinka I, Forcier L. Work related musculoskeletal disorders (WRMDs): a reference book for prevention. London: Taylor \& Francis; 1995.

15. Stock SR, Fernandes R, Delisle A, Vézina N. Reproducibility and validity of workers' self-reports of physical work demands. Scand J Work Environ Health 2005; 31:409-37.

16. Araújo TM, Karasek R. Validity and reliability of the job content questionnaire in formal and informal jobs in Brazil. Scand J Work Environ Health Suppl 2008; 6:52-9

17. Devereux JJ, Vlachonikolis IG, Buckle PW. Epidemiological study to investigate potential interaction between physical and psychosocial factors at work that may increase the risk of symptoms of musculoskeletal disorder of the neck and upper limb. Occup Environ Med 2002; 59:269-77.
18. van den Heuvel SG, Boshuizen HC, Hildebrandt VH, Blatter BM, Ariëns GA, Bongers PM. Effect of sporting activity on absenteeism in a working population. Br J Sports Med 2005; 39:e15.

19. van den Heuvel SG, Heinrich J, Jans MP, van der Beek AJ, Bongers PM. The effect of physical activity in leisure time on neck and upper limb symptoms. Prev Med 2005; 41:260-7.

20. Pedersen MT. Exercise and work-related musculoskeletal disorders in neck, shoulders and low back [Doctoral Dissertation]. Copenhagen: Faculty of Science, University of Copenhagen; 2003.

21. Guérin F, Laville A, Daniellou F, Duraffourg J, Kerguelen A. Compreender o trabalho para transformá-lo: a prática da ergonomia. São Paulo: Editora Edgard Blücher Ltda.; 2001.

22. Nindl BC, Sharp MA. Physical training for improved occupational performance. Indianapolis: American College of Sports Medicine; 2002.

23. Warburton DER, Nicol CW, Bredin SSD. Health benefits of physical activity: the evidence. CMAJ 2006; 174:801-9.

24. Pronk NP, Kottke TE. Physical activity promotion as a strategic corporate priority to improve worker health and business performance. Prev Med 2009; 49:316-21.

25. Polito MD, Maranhão Neto GA, Lira VA. Componentes da aptidão física e sua influência sobre a prevalência de lombalgia. Rev Bras Ciênc Mov 2003; 11:35-40.

26. Fernandes RCP. Algumas características do estudo transversal na epidemiologia ocupacional. Revista de Saúde Coletiva da UEFS 2002; 1:44-9.

27. Baron S, Hales T, Hurrel J. Evaluation of symptom surveys for occupational musculoskeletal disorders. Am J Ind Med 1996; 29:609-17.

28. Pinheiro FA, Tróccoli BT, Carvalho CV. Validação do Questionário Nórdico de Sintomas Osteomusculares como medida de morbidade. Rev Saúde Pública 2002; 36:307-12.

Recebido em 18/Set/2012

Versão final reapresentada em 07/Fev/2014

Aprovado em 18/Mar/2014 